\title{
Language and Linguistics: Frolicking with Some Definitions
}

\author{
Sola Afolayan (Ph.D) $)^{1^{*}}$, Taofeek Olanrewaju Alabi ${ }^{2}$ \\ ${ }^{l}$ Department of English and Literary Studies Ekiti State University, Ado Ekiti \\ ${ }^{2}$ Department of General Studies Federal Polytechnic, Ado-Ekiti, Nigeria.
}

*Corresponding Authors: Sola Afolayan, Department of English and Literary Studies Ekiti State University, Ado Ekiti, Nigeria

\begin{abstract}
This paper provides a scholarly review of selected definitions of language and linguistics. It is not unlikely that the pluralistic definitions of the terms - language and linguistics more often than not, has always led to confusion for scholars who fail to approach the language studies with circumspective disposition. Proceeding from the necessity to clarify the relationship between language and the alleged discipline that probes into its science, the paper reviews some of the extant definitions that have supplied explanations to the field of language and linguistics from Sapir/Saussure to the present times. In the final analysis, the paper provides clear-cut explanations which lead to the finding that while language is a phenomenon that needs linguistics to explain its nature, linguistics needs language to do the explanation. Hence we have a worthy justification for the frolic between language and linguistics.
\end{abstract}

Keywords: language, linguistics, frolic, phenomenon

\section{INTRODUCTION}

Bamisaye (1997) has opined that the question, "what is language does not lend itself to a simple answer". The initiative of this research is also of a similar mindset. Consequently it is with such mindset that we approach the phenomenon language as a rather kaleidoscopic entity in human communicative existence. The very imposing aspect of the term of reference of this study, as can be implied in its title, attempts to reflect on some of the extant definitions of language and linguistics to provide further understanding of the concepts which would possibly make the contents of the chapter veritable investigatory material for budding researchers in the field of language study. Language is such a pervasive human tool that every user of the phenomenon may think he knows what it is in its nitty-gritty. It is however insightful to say that this lame duck, or myopic, claim about language is a product of the misjudgment of the consanguineous relationship between language and man. It is therefore not fortuitous that both Crystal (1974) and Bamisaye and Afolayan (2006) are of the opinion that the amorous rapport between man and language is enough to make anybody fall into the trap of assuming "we know all about it" merely because we speak it.

Strictly speaking, it is possible to speak a language without necessarily 'knowing' the language. Speaking a language is merely the human ability to deploy the organs of speech to articulate its sounds by an individual to communicate intentions in speech-making enterprise. Knowing and understanding the mechanical matrix of the said speech-making activity of man is far-removed from the allowable knowledge of an ordinary speaker of a language. It involves a robust scientific knowledge which is beyond merely speaking the language. The scientific countenance brought into the study of language to shred its components into pieces and conduct multi-angular examinations on it to make it yield its basic properties for better understanding of its typology and dynamics is called Linguistics. Linguistics therefore is a more composite dimension to the study of language. Jonathan Culler explains this further when he draws on what necessitated the evolution of (modern) linguistics:

Before Saussure, the study of language, or philology as it was usually called, had been essentially historical, tracing changes and developments in phonology and semantics between and within languages or group of languages (2000:1). 
In Culler's opinion, Saussure had argued that a scientific study of language which would transit the primordial diachronic study of language and replace it with the synchronic approach was necessary. Definitely because of its scientific methodologies, the post-Saussurean visage of linguistics became more imposing and today, we still make reference to Ferdinand de Saussure as the father of modern linguistics.

The desire to know a language is a desire to understand its formal and functional technicalities. Such a desire will always lead us to linguistics which is simply the scientific study of language. Interestingly, without the robust discourse on language, it would have been impossible to have linguistics. Therefore, the definition of language is contained in the activities of the linguists while that of linguistics is subsumed in the investigation into the form, function, content and context of language. Thus, this paper provides useful insights into the study of language by providing, and reviewing, definitions that can probe into language either via what it is or what it does. A successful accomplishment of the thesis of this paper will no doubt further strengthen the fact that language is the workshop of the linguist and linguistics the science of language. It is therefore apt to note that both language and linguistics are inseparable Siamese twins - the interest in one is an automatic romance with the other. The major reason, perhaps, why Bamisaye (2004:210) notes that "the entity called language has become a phenomenon, and references to its existence have become commonplace. Every normal human being uses language and people also talk about language". The use of language as earlier noted translates to either speaking it or writing it to communicate intentions. As Bamisaye notes, people also talk about language. It is engaging to verify how and what people talk about language. The activity of talking about language is that of using language to talk about itself. Such activity is called linguistics, which is a meta-lingual endeavour that makes language the subject of language. Hence, to define language, one must rely on the materials of language itself, especially since the words, the phrases, the clauses and the sentences are all to be drawn from the entity to be defined.

\section{LANGUAGE: OSCILlating WiThin Notable DEFINITIONS}

Language has been variously defined by scholars depending on their idiosyncratic views of the phenomenon. Amidst the pluralistic definitions variously provided by language researchers, Edward Sapir's enjoys prominence and it suffices to make it operate at the center of this section of the paper. In Language: An Introduction to the Study of Speech, Sapir notes that language is "a purely human and non-instinctive method of communicating ideas emotions and desires by means of voluntarily produced symbols" (1921:8). Sapir's motivation might not have been far-removed from that of the influential progenitor of science-driven study of language, Ferdinand de Saussure, who had defined language as "a system of signs that expresses ideas" which is "therefore comparable to the system of writing, the alphabet of deaf-mutes, symbolic rites, polite formulas, military signals, etc" (1966:16). Saussure's definition cited here, though well-encapsulating, seems a bit silent about language being "purely human". For Sapir to have noted this specific trait of language indicates an excommunication of other animals from the guild of language users and this is a step away from Saussure's opinion.

To dwell on Sapir's notion of "purely human" is to give stridency to the fact that language is specie specific and this authenticates man as the de facto owner of language. This serves as the motivation for Noam Chomsky to also insist that "...language appears to be a unique phenomenon, without significant analogue in the animal world" (2000:4). The Specie specific tendency of language has formed the core of several attempts to explain what language is (Odebunmi 2016 Aderibigbe 2004, Adegbite and Akindele 2005, Radford 2009, Amuseghan 2000, etc). Hence, the desire to present language as a purely human entity is an aspect of Sapir's "serviceable definition of language" which appropriates the localization of speech in the human brain. This alone has triggered various research projects that have further subjected language into more profound assessment (Griffin and Ferreira 2006, Weisme 2006, Afolayan and Bamisaye 2014, Field 2004, Gleitman and Landau 1994 Goodman 1967, etc).

Sapir clarifies what he means by "non-instinctive" when he furthers the explanation that

There is no discernible instinctive basis in human speech as such, however much instinctive expressions and the natural environment may serve as a stimulus for the development of certain elements of speech, however much instinctive tendencies, motor and other, may give a predetermined range or mold to linguistic expression (9). 
It is obvious that in Sapir's opinion, language is though non-instinctive, but it is prone to human instinct to react to the milieu and provide continuous response(s) to his environment. Sapir provides a soft landing for his definition as he establishes language as purely and sophisticatedly made to transcend all other forms of communication prevalent among non-human animals. We can share Sapir's perception that "such non-human animal communication brought about by involuntary, instinctive cries is not, in our sense, language at all" (8). Sapir claims that language is not merely those instinctive cries that communicate intentions. For him, language is a product of methodical processes that start in a pre-verbal state that precedes articulation.

Similarly, H.G. Widdowson (1975:20) asserts that language is "a system of arbitrary vocal symbols which permit all people in a given culture, or other people who have learned the system of that culture, to communicate or to interact". Not minding the spatial difference in time, both definitions from Sapir and Widdowson exhibit noticeable purposive synergy in the belief of what language is. For instance, language in Sapir's term is an aftermath of "voluntarily produced symbols" while it is "arbitrary vocal symbols" for Widdowson. One can deduce from both definitions that it is not unlikely that both scholars would have implied the same connotations in their deployment of the words "voluntarily" and "arbitrarily". In a nutshell, when Sapir further provides the explanation that "[t]here are, properly speaking, no organs of speech; there are only organs that are incidentally useful in the production of speech sounds" we know that the activities of speech making are not part of the primary functions of the said speech organs. What translates to speech making contraptions and mechanisms are the orchestrated voluntary services of the organs whose biological functions are tailored towards human survival. Strictly speaking, all the lungs, the larynx, the teeth, the tongue, the nose, etc have their primary functions programmatically linked to man's physiological needs towards his survival. Widdowson's initiative to capture language as coordination of "arbitrary" symbols may reinvigorate the echolalia of Saussure's celebrated conviction that "the link between signal and signification is arbitrary. Since we are treating a sign as a combination in which a signal is associated with a signification, we can express this more simply as: the linguistic sign is arbitrary" (12). Saussure had meant to say that there is not a one-to-one correlation between the name given to an object and the object itself and by insisting on arbitrariness of language, according to Robert Scholes, "Saussure made extra-linguistic influences on language apparently irrelevant" in the well-formedness of its sound iconographies (13).

Widdowson deployment of the term "arbitrary" suggests that the speech sounds are picked for usage with serendipity and not by any pre-planned order. Therefore given the tableau of operation set for this study, it is not out of place to see both Sapir's connotation of voluntarily and Widdowson's initiative of arbitrary as operationally associated in the desperate attempt to define language.

Osisanwo (2003:1) moves a step further when he opines that language is better defined as "the human vocal noise or the arbitrary representation of the noise used systematically and conventionally by members of a speech community for the purpose of communication". Both Sapir and Osisanwo have identified the sound properties of language in the use of "voluntarily produced symbols" and "vocal noise". By extending the scope of his definition to the properties of the graphetic representation of the sounds, Osisanwo has initiated a definition that does not set the limit of language to the spoken species alone. From Osisanwo therefore, conclusion can be drawn that language does not stop at the oral sounds employed physically when speaking but also to the representation of the said sounds on paper such that the impression communicates the initiator's intention (Bamisaye and Afolayan 2006).

So far, specific seminal definitions of language have been highlighted, with Sapir's definition at the center of the discussion. Sapir's indication that language is non instinctive and a method of communicating idea is an indication that he meant to define language from two axes - the axis of nature of language and the axis of function of language. In like manner, ensuing definitions after Sapir can be grouped to reflect language either in its natural properties or through its basic functions in the society. In its nature, according to Odebunmi, "language has intrinsic resources, with naturally systematized or ordered components, which when mastered by humans, are used in society for intrasocietal and inter-societal communication" (2016:5). These intrinsic resources of language have been labelled as "system of signs", "arbitrary vocal symbols", "voluntarily produced symbols" et cetera by most of the definitions already cited. The resources are the noticeable linguistic sounds that are only traceable to the architecture of language, which make the phenomenon uniquely or purely human. 
Odebunmi sees language as "a distinctive human endowment that has empowered the human race with expressivity" (2016:3). Odebumi explains that his own definition is subsumed in that of Smith which claims that language is:

a learned, shared and arbitrary system of vocal symbols through which human beings in the same speech community or sub-culture interact and hence communicate in terms of their common cultural experience and expectations(1969:9).

It is obvious that Smith's definition encapsulates both the (nature) form and function of language and this trait is typical of most modern definitions of language. Therefore, rather than emphasize only on the typological properties of language, the modern linguist strives to define language both from the formal/natural properties and functional entailments. For Odebunmi therefore, language can better be defined both from its natural properties and functional potentials. Odebunmi provides some guiding principles for the definition of language via its nature. Four of them listed below are used as support for this paper.

- Acquisitional Nature

- Specie-Restriction Nature

- Arbitrariness Nature

- Rule-Governed Nature

\subsection{Language Defined as Product of Acquisitional Activities.}

According to Odebunmi, "the acquisitional nature of language maintains that language does not come to man automatically" (5). Griffin and Ferreira initiate this assertion when they state that "whereas people typically recognize the words in their native language quickly and automatically, the same words require an intention to speak and can take over five times longer to generate than to recognize" (2006:21). Griffin and Ferreira make this claim in their attempt to enumerate the procedures of language production as rather hectic. In fact, they evolved the model below to support the fact that language is a product of systematized activities.

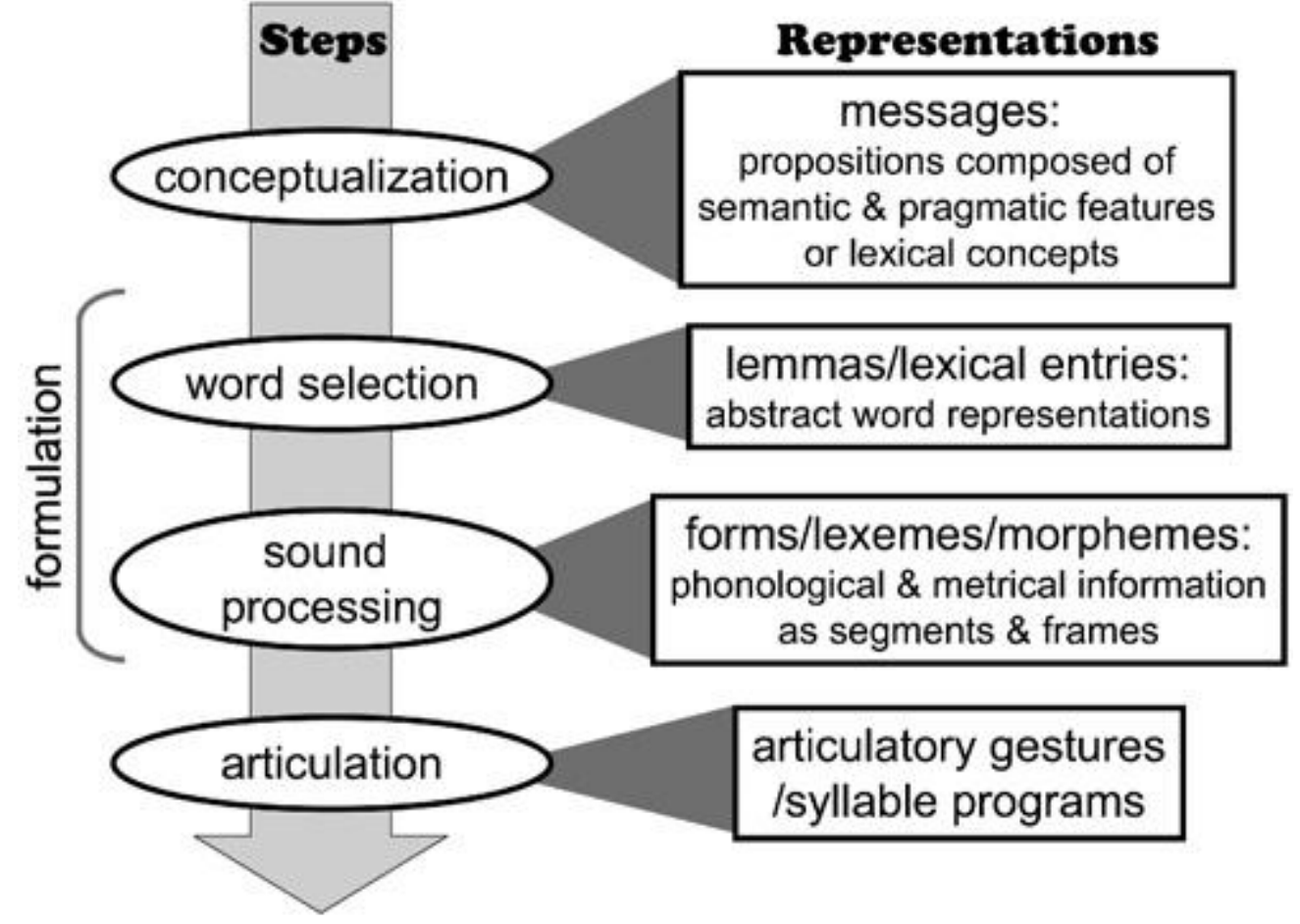

Figure1. Steps in Language (Culled from Griffin and Ferreira, 2006)

Griffin and Ferreira also provide a comprehensive explanation to this model giving its analysis thus:

Language production is logically divided into three major steps: deciding what to express (conceptualization), determining how to express it (formulation), and expressing it (articulation).Although 
achieving goals in conversation, structuring narratives, and modulating the ebb and flow of dialogue are inherently important to understanding how people speak ...((1989: 21).

Also looking at language from this perspective, Chomsky's opinion of language that it "is a basic instinct for humans since we are all born with an innate knowledge of grammar that serves as the basis for all language acquisition" becomes handy to substantiate Odebunmi's claim that language is a product of acquisitional processes. Language can thus be defined within this parameter as the methodical human communication vehicle procedurally derived from man's acquisitional insticts.

\subsection{Language Defined as Specie Specific}

According to Odebunmi, the specie restriction nature of language lies in "the exclusive association of language with humans" (5). This particular trait of language has been captured in specific definitions of language. Also notable among such definitions are those of Sapir and Chomsky already cited above which appropriate language as "purely human" and "unique phenomenon". Here, it would be rewarding to cite some other definitions against the risk of undue repetitive emphasis on Sapir and Chomsky. In the words of Andrew Radford (et al), language is "a cognitive system which is part of any normal human being's mental or psychological structure" (2009:1). Radford's opinion also correlates with that of Goodluck's (1991), who views language as a fundamental part of the human genome, which is a trait that makes humans unique beings, and its acquisition is a natural part of maturation. Wikimedia Project explains this further:

It seems that the human species has evolved a brain whose neural circuits contain linguistic information at birth and this natural predisposition to learn language is triggered by hearing speech. The child's brain is then able to interpret what she or he hears according to the underlying principles or structures it already contains (Wikimedia Project, 2015)

For a definition to be sensitive to the specie-restriction profile of language, it must align itself with the countenance to label language as the exclusive belonging of man which no other communicating creature shares with him. Language can consequently be explained as the man's property exclusively created to meet his socio-cultural mandates of communication and interaction with his environment.

\subsection{Language Defined in its Arbitrariness Nature}

The notion that language is arbitrary is a celebrated aspect of Saussure's programme. In his own definition, Saussure itemizes language among the other semiotic systems claiming that "...it is the most important of all these systems" (16). Further explaining the nature of language, Saussure notes that it is built on the scaffold of signs with the claim that an instance of the linguistic sign will always produce two aspects - the signifier and the signified. Consider the following diagram:

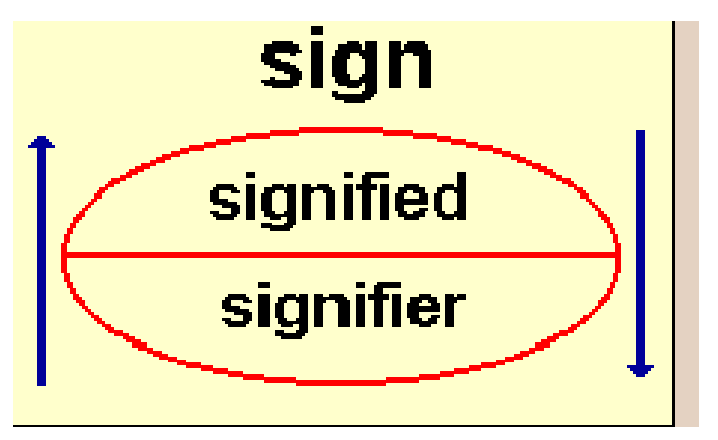

Figure2. Saussure's sign schema (culled from David Chandler)

In the diagram, as explained by Chandler, sign is the whole that results from the association of the signifier with the signified and,

[t]he relationship between the signifier and the signified is referred to as 'signification', and this is represented in the Saussurean diagram by the arrows. The horizontal line marking the two elements of the sign is referred to as 'the bar'....A sign must have both a signifier and a signified. You cannot have a totally meaningless signifier or a completely formless signified. A sign is a recognizable combination of a signifier with a particular signified (16). 
What Saussure referred to as the arbitrary nature of language is the fact that the relationship between the signifying sound and the signified concept is arbitrary. Odebunmi explains this further when he notes "arbitrariness points to language being a set of symbols interpretable only on the basis of human shared conventional knowledge of language code as mentioned earlier" (5). Perhaps the initiative to view language is "purely human", insisted upon by Sapir, lies in the fact that language needs man to evolve at all and a world without man is a world bereft of language. Language is a naming device whose evolution depends solely on man's instinct to give names to objects and events. Since man's naming of objects is based primarily on socio-cultural intuitions and communal agreement it is said to be arbitrarily done. Hence language is arbitrary. Language is then the child of necessity created from man's arising necessity to provide definition for the world around him. This is adequately corroborated by The Holy Bible as it states

...God formed every beast of the field, and every fowl of the air; and brought them unto Adam to see what he would call them: and whatsoever Adam called every living creature, that was the name thereof. And Adam gave names to all cattle, and to the fowl of the air, and to every beast of the field;... (Genesis 2:19-20)

Neither Bible scholars nor linguists have been able to provide the naming yardstick that Adam used up till today except to cling to the Saussurean position that Adam's activity was premised on arbitrariness.

\subsection{Language Defined as Rule-governed Phenomenon}

To accept that language evolved out of voluntarily and arbitrarily produced symbols is not to suggest that things happen without rules in language production. In the words of Noam Chomsky, language is "a set of (finite or infinite) sentences, each finite in length and constructed out of a finite set of elements." Chomsky further clarifies the rule-governed nature of language as he points out that "language is a process of free creation; its laws and principles are fixed, but the manner in which the principles of generation are used is free and infinitely varied". Chomsky considers language unit as such inputs which are arranged within the custody of the brain from where they are always given specific semiotic rule-governed functions. Subsequently, in A Minimalist Program for Linguistic Theory, Chomsky explains;

The human brain provides an array of capacities that enter into the use and understanding of language (the language faculty); these seem to be in good part specialized for that function and a common human endowment over a very wide range of circumstances and conditions (2004:1).

For Chomsky, language faculty is a product of the rule-governed activities of language production and comprehension which follow certain regimental patterns of occurrence.

Similarly, Julie Amberg and Deborah Vause (2015:5) provide more elaborate explanation to language as a rule-governed entity when they posit:

Saying that language is rule-based usually makes people think of other kinds of situations where rules are enforced by a particular authority. For example, think about classroom behavior. Students are expected to sit still, be quiet, pay attention, and so on; typically, there are consequences if they don't follow these rules. Language rules, however, are not enforced by any authority figure; language police do not exist. Instead, language rules are conventions. This means that they come into existence through common practice by users of the language rather than through the imposition of an authority figure. As a result, members who use the language conventions of their particular community may not even be conscious of following them.

Odebunmi is therefore in order to claim that defining language via its rule-governed tendency involves the portrayal of the phenomenon as "a system" and a "system of systems" adding that

while the former indicates the uniqueness of every language in terms of sounds, structure and vocabulary, the latter shows the subsystem that emerge from the phonological, grammatical and lexical systems of all languages(5).

If it is necessary to evolve a working definition from the rule-governed nature of language, one may also be correct to assume that language is an aftermath of the rule-governed movements and 
placements of human's anatomical structures in the bid to evolve decodable audible sounds meant for communication.

Irrespective of the definitions adopted for language, what is important to emphasize is that any definition that is silent on its basic function, which is communication, is not worth mentioning. Thus in the opinion of Amberg and Vause, those who study language may disagree over a precise definition "because they dispute some concepts, such as whether or not language must have a written and/or oral component" but what cannot be controverted is the fact that language is a rule-based system of signs whose topical function is to communicate man's mind (5).

\subsection{Language Defined in its Functional Capacities}

If the various definitions of language have adduced to it as the embodiment of human basic communication procedures, then the major functional responsibility is communication. For Odebunmi, this function of language could be intra-society or inter-society and this

Projects three basic functions of language: descriptive, expressive or vocative and prescriptive (Handout 5 logical functions of language: nd). In its descriptive function, language provides information, states facts, refers to things, persons and properties and presents issues in all their dimensions....The expressive or vocative language evokes language users' psychological or emotional state....Prescriptive language is used in giving directives, orders and instructions (5).

It is not unlikely that Odebunmi's frame of mind evolved from Halliday's initiative to define language as a system of functional structures whose primary aims are to add meanings to reality. In the Hallidayan term, the most fundamental function of language lies in its use as a vehicle of meaning. Halliday himself explains the integral fact of his popular Systemic Functional Linguistics (SFL) in an interview with G. Kress, R. Hasan and J. R. Martin in 1986 when he responded

If language is evolved as a way of constructing reality - then it is to be predicted that the forms of organisation of language will in themselves carry a model of that reality. This means that as well as being a tool, language will also be metaphor for reality. In other words, the patterns of language will themselves carry this image, if you like.

This is what I would understand by talking about a 'natural' grammar.

The only way language constructs reality and also serves as the "metaphor for reality" is through its production of meanings to things in reality. Language is therefore a macrocosmic and super-ordinate entity which parades microcosmic meaning-carrying structures that interact syntagmatically to evolve understandable units that give substance to reality. Consider the opinion of Amrin Saragih expressed below to capture the multi-directional functions of language

Firstly, functional approach to the study of language is based on the principle that language is structured in response to the needs of people as social beings....In this way language evolves in line with human needs for language in their social settings. In other words, this implies that the structure of language in use or rather the structure of text is motivated and determined by needs of the society where the language is used (2008:6).

The function of language is therefore crucial to its existence and this is why it is the constant desire of language researchers to make language nature, as well as its function, the talking point. As earlier implied, the requirement to discuss a language is beyond the ability to speak the language. The field of study which has evolved from the analytic discussion of language is Linguistics.

\section{The Science of Language: A Re-Appraisal of Saussure an Linguistics}

It seems a commonplace knowledge that linguistics is the scientific study of language since several publications have established this fact (Saussure 1915, Meyer 2009, Radford et al 2009, Bamisaye 1997, Afolayan 2004, Lyons 1968, Abiodun 2004, O’Grady 2000, Fetzer 2004, Scholes 1974, etc). It is also the practice to label Ferdinand de Saussure the Father of Modern Linguistics mainly because he spearheaded the radical departure from the old ways of language analysis. However, if there was anything called linguistics before the publication of Course in General Linguistics (1915), a book posthumously credited to Saussure, its practitioners might not have been scientific in their approaches 
especially given the circumstance that the noticeable difference between the earlier version of linguistics and the (post) Saussurean linguistics is the frenzy to apply the logic of science to language. The reason for this assertion is not far-fetched. It lies in the fact that one is bound to assume that the brand of linguistics practiced before Saussure might be unscientific and unanalytical if Saussure's argument cited below is anything to go by.
A science that studies the life of signs within society is conceivable; it would be a part of social psychology and consequently of general psychology; I shall call it semiology (from the Greek semeîon 'sign'). Semiology would show what constitutes signs, what laws govern them. Since the science does not yet exist, no one can say what it would be; but it has a right to existence, a place staked out in advance. Linguistics is only a part of the general science of semiology; the laws discovered by semiology will be applicable to linguistics, and the latter will circumscribe a well-defined area within the mass of anthropological facts (Saussure, 16).

In the quotation, expressions such as "conceivable", "would be" and "since the science does not yet exist" are pointers to the fact that Saussure was introducing a fresh dimension to the study of language.

Saussure's motivation to inject science into the study of language is never unconnected with his interest in Structuralism, a theory which was more like the exhumation of the carcasses of the moribund formalist approach to language and literature. Formalism it was which insisted on the foisting of scientific countenances on the language of literature to initiate objectivism. Therefore, to know that Roman Jakobson, one of the strong members of the Prague Linguistic Circle, played important roles in formulating the fundamental principles of the Russian Formalism is to discover that the scientism found in Structuralism is traceable to Formalism. A scholar of structuralist intent is no doubt a science-oriented individual and it is not a coincidence that Saussure had toed the line he had chosen in the discussion of language. Thomas Schmitz provides further explanation.

Like the Russian Formalists, Saussure believed that it was necessary to give a more precise definition of the field he was exploring. He distinguished two aspects of language [315.77]: on the one hand, the single utterance (parole) and on the other hand, the system of rules that underlies these utterances (langue) (2007:27).

Sausure's permutation makes language a "system of signs" and modern linguistics, which he labelled Semiology, the science of the system of signs. Meyer thus concludes:

Like a biologist studying the structure of cells, a linguist studies the structure of language: how speakers create meaning through combinations of sounds, words, and sentences that ultimately result in texts -extended stretches of language (e.g. a conversation between friends, a speech, an article in a newspaper). Like other scientists, linguists examine their subject matter - language - objectively (2).

The interest to swing away from the traditional diachronic study of language and adopt the synchronic method of analysis makes Saussure's approach monumental. Differentiating between both approaches to language provides linguists two options of analysis, either to see the materials of language as part of historical sequence, or as part of a total system simultaneously within itself. By adopting the latter of the two approaches, the modern linguist has joined Saussure to go scientific and the aftermath of this is the emergence of different subfields within linguistics.

\subsection{Linguistics: Its Branches}

As already implied, the simplistic philological models of the traditionalist were toppled by the more scientific views on language and the consequence is the opening of different windows of analysis especially drawing from Saussure's statement that "language in its entirety has many different and disparate parts" (1993:03). The statement buttresses the foundation of the tripartite study of language from the phonological, syntactic and semantic angles. These angles were later to initiate the area of linguistics labelled as Theoretical Linguistics. 
Theoretical linguistics enables the linguist to study "linguistic structure as his primary concern and relate all other manifestation of language to it" (Saussure 1993:3). To expand Saussure's definition of Theoretical linguistics we can echo an earlier submission that it deals with theories which describe and characterize language via notable angles of its manifestations. For instance, theorizing about how the spoken words are accentuated has led to the study of Phonology. The Theoretical linguist recognizes language as a structured pattern which is both a self-contained whole, and at the same time society-sensitive and then factors these realities into scientific observation of language. The view of language as a society-sensitive phenomenon suggests that linguistics does not only thrive in the language-for-language's-sake parameter. The field also extends in scope to areas of language functions and application in the society. This suggests that linguistics can also be applied apart from being theoretical. We can thus draw the conclusion that linguistics can either be realized as Theoretical Linguistics or Applied Linguistics. Under both approaches to language, a miscellany of analytical options has emerged. The following scheme, drawn from Afolayan (2009:9), provides a picture of the likely branches of linguistics.

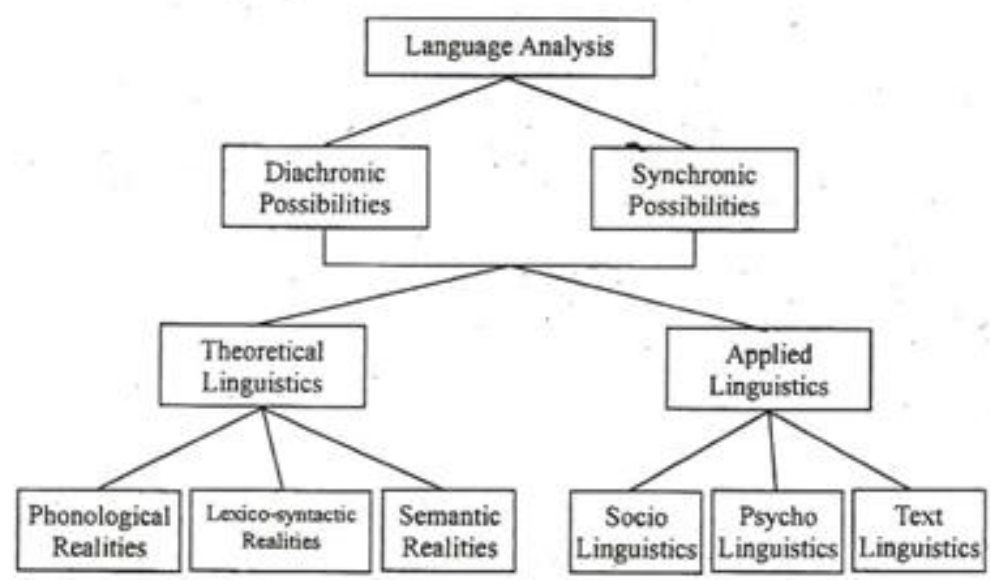

Figure3. Branches of Linguistics (culled from Afolayan 2009)

The scheme above provides an insight into how the Saussurean logic became the foundation for the countenances of Theoretical and Applied Linguistics. Theoretical Linguistics splits into three linguistic realities - phonological, lexico-syntactic and semantic. Applied linguistics is the field of linguistics which marries the study of language with the divergent fields of human endeavours which may be extraneous to language itself. In the scheme therefore, it is possible to view the connections with the likely disciplines that intersect with the use of language in human society.

Today, so many areas of Applied linguistic studies have evolved as scholars' attempt to understand language from what it is and what it does in the society. The apologists of Applied Linguistics, according to Finegan, apply "the findings of their disciplines to the real-world problems" in matters ranging from educational peculiarities to language uses and policies (2004:23). In what follows, Ibitoye elaborates the praxis of Applied Linguistics.

First, it must be stated that Applied Linguistics must not be seen as another theoretical approach to language studies. Applied Linguistics does not create (or introduce) new theories of language. Rather it attempts to harness and use all the insights and discoveries brought about by the investigations of the other arms of linguistics in the effective teaching and learning of language and communication. In other words, Applied Linguistics applies linguistic and non-linguistic discoveries and insights in an integrated way to practical matters like language teaching and communication (2004:239).

The table below shows some of the fields under linguistics.

\begin{tabular}{|l|l|}
\hline Theoretical & Applied \\
\hline Phonology & Psycholinguistics \\
\hline Syntax & Sociolinguistics \\
\hline
\end{tabular}




\begin{tabular}{|l|l|}
\hline Semantics & Computational Linguistics \\
\hline \multirow{5}{*}{} & Mathematical Linguistics \\
\cline { 2 - 2 } & Historical Linguistics \\
\cline { 2 - 2 } & Cognitive Linguistics \\
\cline { 2 - 2 } & Neurolinguistics \\
\cline { 2 - 2 } & Pragmatics \\
\cline { 2 - 2 } & Pedagogical Linguistics \\
\cline { 2 - 2 } & Forensic Linguistics \\
\hline
\end{tabular}

To define linguistics as a scientific study of language is not in any way to imply that the praxis of the field is straightforward. The few disciplines and sub-disciplines arranged on the table are merely instances of the multi-facetted realizations that the study of language via the moves that science has initiated. The left wing of the table exhibits instances of Theoretical Linguistics while the right wing reveals implications in Applied Linguistics. Areas of core linguistics like morphology and phonetics are not indicated because to a large extent, they can be assumed to have been accommodated within syntax and phonology respectively.

\section{CONCLuSion}

In the introduction of this paper, the fact that language is not too easy to cramp into one all-containing defining sentence has been expressed. Not minding this fact, the paper still set out to present, and review canonical definitions that can shed more light on the phenomenon. Quite often as we review specific definitions the discovery is made that constant recourse to linguistics is inevitable. This is notably because the suppliers of those definitions are accomplished linguists who have immersed themselves in the study of, analysis of, and theorizing with, language. The opinion of Sapir directs the discussion of language and the scholarly positions of linguists like Saussure, Chomsky, Odebunmi, Bamisaye et cetera are further used as supports for the claim that language is not only purely human but also needs humans to exists, at all, and subsist.

It raises a conundrum if one grapples with the fact that man needs language to survive as much as language needs man to excel. Also for linguistics to exist, language must be involved to provide the linguist his utterance on language. Thus, man, language and linguistics form the compatible members of a tripartite whose union will survive the test of time. While language is a fundamental part of human communicative activities, linguistics is part of man's activities on his activities that warrant language use. In as much as language exists and man is able to talk, one of the things he would always like to talk about is his language. This is a statement that language is man's lingual activities and linguistics is the product of his multi-facetted meta-lingual activities.

\section{REFERENCES}

[1] Afolayan, S.O. (2004) "Introduction to Textlinguistics" in Bamisaye, T.O. (Ed) An Integrated Study in Language and Society Lagos: MAJAB pp 109-140.

[2] Afolayan, S.O. (2009) The Chronics of Language: An Applied Linguistic Contemplation Ibadan: ARRIDAA Graphics.

[3] Amberg, Julie S. and Deborah J. Vause (2015) American English: History, Structure, and Usage Cambridge: Cambridge UP

[4] Bamisaye, T.O.(1997) (Ed) Studies in Language and Linguistics: An Introductory Text: Akure: Mortem Paperbacks

[5] Bamisaye, T.O. (2004) "An Overview of Sociolinguistics and the English Language in Nigeria" in Bamisaye, T.O. (Ed) An Integrated Study in Language and Society. Lagos: MAJAB

[6] Bamisaye, T.O. and Afolayan, S.O. (2006) Basic English Structure and Literary Studies Lagos: King Julius Educational Publishers

[7] Chandler, Daniel (2000) "Semiotics for Beginners" [www document] URL http://wwwaber.ac.uk/ media/documents/s4B/semiotic.html.

[8] Chomsky, N. (2002) Syntactic Structure Berlin: Walter de Gruyter GmbH \& Co. KG,

[9] Crystal, D. (1994) What is Language London: Edward Arnold Ltd. Culler, J. (2000) Literary Theory: A Very Short Introduction Oxford: Oxford University Press.

[10] Goodluck, H. (1991). Language acquisition: A linguistic introduction. Malden (MA): Blackwell Publishing Ltd. 
[11] Griffin, Z.M. and Ferreira, V.S. (2006) "Properties of Language Production" in Traxtler, M.J., Gernsbacher, M.A. Handbook of Psycholinguistics $2^{\text {nd }}$ Edition Amsterdam: Elsevier Inc.

[12] Halliday, M.A.K. Interview with G. Kress, R. Hasan and J. R. Martin; May 1986 posted by J.R. Martin, March 29, 2005 Linguistics Online

[13] Ibitoye, C.A. (2004) "Fundamentals of Applied Linguistics" in Bamisaye, T.O. (Ed) An Integrated Study in Language and Society Lagos: MAJAB pp235-258.

[14] Odebunmi, A. (2016) "Language, Culture and Society: A Theoretical Anchorage" in Odebunmi, and Ayoola, K. (Eds) Language, Context and Society: A Festschrift for Wale Adegbite Ile Ife: OAU University Press.

[15] Osisanwo, W. (2003) Introduction to Discourse Analysis and Pragmatics Lagos: Femolus-Fetop.

[16] Radford, A., Atikson, M., Britain, D., Clahsen, H. and Spencer, A. (2009) Linguistics: An Introduction Second Edition, Cambridge: Cambridge University Press.

[17] Sapir, E. (1921) Language: An Introduction to the Study of Speech New York: Harcourt Brace

[18] Saragih, A. (2008) Introducing Systemic Functional Grammar Medan: University of Medan Press

[19] Saussure, D. F. (1993) "The Object of Study” in Lodge, D. (Ed) Modern Criticism and Theory: A Reader. London: Longman pp1-14.

[20] Saussure, D. F. (1966) Course in General Linguistics New York: McGraw Hill.

[21] Schmitz, T.A. (2007) Modern Literary Theories and Ancient Texts Oxford: Blackwell Publishing.

[22] Scholes, R. (1974) Structuralism in Literature: An Introduction London: Yale University Press.

[23] Smith Jr, R. (1969) "Language and the Total System of Communication" in Archibald, A. (Ed) Linguistics Today New York: Basic Book pp 23-35.

[24] The Holy Bible The Authorized King James' Version. USA. The Gideonites

[25] Widdowson, H.G. (1975) Language Teaching Text: A Manual For Teachers London: Oxford University Press.

[26] Wikimedia Project Modified version of February 4, 2014 Mediawiki, Wikiversity.

Citation: Sola Afolayan (Ph.D), Taofeek Olanrewaju Alabi. "Language and Linguistics: Frolicking with Some Definitions” International Journal on Studies in English Language and Literature (IJSELL), vol 9, no. 7, 2021, pp. 22-32. doi: https://doi.org/10.20431/2347-3134.0907002.

Copyright: (c) 2021 Authors. This is an open-access article distributed under the terms of the Creative Commons Attribution License, which permits unrestricted use, distribution, and reproduction in any medium, provided the original author and source are credited. 